\title{
Teaching Hinduism through a Rural Homestay in South India
}

\author{
Edward T. Ulrich \\ University of St. Thomas
}

\begin{abstract}
:
For the first time, in 2008, I offered a world religions study abroad course in South India. The special emphasis was meeting and befriending locals, and the centerpiece of the course was a sixnight stay in rural homes. I considered this immersion in a Hindu context to be the best setting for learning Hindu thought. However, the environment was not conducive to that, since there were many other issues that seized the students' attention. All the same, they learned a great deal about Hinduism, mainly in terms of the values that govern the homes and villages. Redesigning the course to better utilize the rich learning opportunities of the countryside involved addressing issues such as hospitality, gender roles, religious pluralism, material poverty, and environmental pollution, all of which seized the students' attention.
\end{abstract}

\section{A Vision for a Course 1}

In my early years as a professor of theology with expertise in comparative religion, I decided to design a January Term course set in South India. The course would focus on several world religions, with a special emphasis on Hinduism. The course would meet liberal arts requirements and would be designed for predominantly Upper Midwestern students with Catholic and Protestant backgrounds.

To plan my course I surveyed some other, short-term courses in India. I noticed, among these courses, a stereotypical route among major sites. In addition, I had heard from staff in international education at my university that a typical shortcoming of study abroad courses is that the participants interact only with other travelers and do not come to know and meet any locals. My plan for the course was thus to set the experience mainly in the countryside, away from major sites, and to focus on the people, not on sites. The highlight of the course would be a six-night stay in a village during the Pongal harvest festival.

Further, I wanted the students to immerse themselves in the Indian context, not simply be tourists traveling through, merely gazing at the different sites and merely being entertained by the experiences. I wanted them to participate in the culture, and to learn thereby. Thus, I spent a lot of time, both before the trip and during it, discussing with the students the appropriate manners, etiquette, and customs. Also, rather than moving quickly from site to site we would stay at particular sites for several days, to give students a chance to experience them more deeply, and to meet people. Beyond meeting people, I encouraged the students to befriend them. Students at my university tend

\footnotetext{
${ }^{1}$ I am grateful to the Upper Midwest Association for International Education, and the College of Arts and Sciences at the Univesity of St. Thomas for funding my first two trips to India, and for their support and encouragement as I ran the course in subsequent years. I am grateful to the series of research assistants who transcribed journal entries over the years. I am especially grateful to Kelsey Heinert for her hard work transcribing and coding the journal entries.
} 
to be fun loving and sociable, and students who applied for the course welcomed these goals and plans.

This paper will cover several issues. First, it will show what I planned and intended and what, in the first run of the course, actually happened on-site. The paper will then explain why things went differently than planned, and what I, as the professor, needed to learn. Next, this study will show what the students did learn, though different from what I had intended, from their exposure to the religious culture. The paper will show this through selections from examinations and journal accounts, which were a part of their homework assignments on-site. The last section of this paper will discuss some pedagogical approaches I developed over the four times I ran the course.

\section{Planning the Specifics of the Course}

My approach was to locate the course in an area of which I had previous knowledge and where I had some contacts. This meant locating the course in Tamil Nadu. I also included the neighboring state of Kerala. Thereby students would be exposed to two different regional cultures, coming to appreciate India's variety and diversity. Also, Kerala was the home to some of India's earliest Jewish, Christian, and Muslim communities, so it would afford learning opportunities in those religions. Before offering the course, I came to know these areas better through travel, reading, and developing relationships with locals.

In terms of pedagogy, I planned to illustrate broader themes of Hinduism and other religions through local expressions. For instance, the town in Tamil Nadu where the homestay would take place, has temples to both Shiva and Parvati. This would give me an opportunity to discuss the theological issue of the relationship between the supreme deity and his spouse. An hour from the town is a major Shaivite site, and thus I could discuss some of the legends of Shiva. Also, nearby there are Hindu, Jain, and Roman Catholic hill shrines, affording opportunities to discuss the role of hills in Tamil religion. Further, the presence of Hindu, Jain, and Catholic religious institutions would give opportunities to explore the importance of lifestyles of asceticism and renunciation. Last but not least, the vibrant presence of these religions in close proximity to each other would demonstrate the positive relationships that can exist between religions. In addition to lectures and readings on religion, students were assigned chapters from Sashi Tharoor's India: From Midnight to the Millennium and Beyond. This book gave students a good, introductory grasp of contemporary Indian society.

I designed the course as a deepening immersion in Indian culture. It began in Kerala, which is a relatively cosmopolitan and affluent state, and which has pleasant natural scenery. Certain areas of Kerala also have a strong Christian presence, with communities that stem from the first millennium. By beginning the course in Kerala, students were initially in environments more familiar, and thus more comfortable, to them. In the first week, students stayed at an Indian Catholic retreat center, which, while plain and simple, was clean and spacious. That was our base from which we made excursions into the countryside, meeting people and visiting sites.

After leaving the retreat center, we stayed in a series of three hotels, two of which were considerable steps down in terms of physical comfort. Then we began our six-night stay in rural homes. By staying in homes, I moved traditional learning and pedagogy into a living space. The goal was not simply to observe, but to share as much as possible in the lifestyle and culture of the host 
families, forming relationships with them. After that, we continued our journey through Tamil Nadu, staying in three more hotels, two of them being nice ones, and the final one, in Mahabalipuram, being luxurious. That final stay was a chance for the students to relax, to recover from any lingering, minor illnesses, and to be in good spirits for the return journey to the United States.

In terms of relating to the people and adapting aspects of the culture, I emphasized several things. First, we followed Indian dress codes, and to some extent, wore local clothing. We followed basic etiquette, such as not smoking in public and not making physical contact with opposite genders, both in terms of the Indians and our own group. I advised students to pack with caution, avoiding appearances of affluence, in order not to highlight the differences between ourselves and the local people. Also, whereas young Americans love to "go out," Tamil villagers love to be at home, enjoying tea with family. I explained to the students that the homestay experience would not be about seeing sites but about sharing in the life of the family. Further, I explained that the family would dictate many aspects of daily life to the students, and that they should cooperate to show their gratitude to their hosts and to enter more deeply into the culture.

The students needed considerable preparation for such an immersion. The first time I ran the course, I gave each student an hour-long interview when he or she applied for the course, and spent a day in orientation before the trip. In later years, in conjunction with former students, the association coordinating the experience, and health services at my university, there were an hourlong interview, online orientation materials, an hour of online orientation, an evening of orientation, and one full morning. Further, on-site I held a series of orientation sessions, most short and one long. These many sessions grew in conjunction with needs and issues that came up on-site in prior years. They made for smoother experiences for the students, and better experiences for the Indians, too.

\section{The First Run of the Course}

My vision and plans might all seem to have been good. Indeed, the course went spectacularly well during the first ten days. However, things fell apart in the first hours of the homestay. The material poverty and the alien cultural context sobered the students considerably, even leaving some in tears. One student, referring to Tharoor's India, expressed his feelings thusly: "Tharoor gave a truly in depth look at the Indian people in his book, and this gave us all what we thought to be a good understanding of an Indian's life. However, the absolute shock that occurred on the first night of the home stay dispels the notion that we comfortably knew what to expect. No book could have prepared us sufficiently, not even one written as well as Tharoor's. . The family I stayed with chose only to have their necessities of life. They lived simply, sleeping on the floor together, eating on the floor, and had no unnecessary decorations, etc." (2008 E1). Another student wrote, "I've got to say, the home stays were extremely difficult at first. . I couldn't believe how different their lifestyle was from mine. Their house had one bedroom, a kitchen, and an entryway with a t.v. and two plastic chairs in it. The toilet (a.k.a. squat pot out house) and the bathing room out house were across the roof (outside)" (2008 J.4).

My role as professor suddenly changed from an academic lecturer to looking after students, putting up mosquito nets, procuring mattresses, checking on drinking water, and taking students to 
the doctor. Further, the lectures I had prepared with care and attention meant nothing to the students. Ironically, we were in a region saturated with Shiva worship, but my lectures on Shiva rang hollow and empty. The reason was that the minds of the students were flooded with a host of other issues, including poverty, race, class, gender, and environmental pollution.

Although my lectures on religion seemed irrelevant, religion was central to the experiences of the students. In fact, religion captivated the students' attention and transformed their experiences of the small town from negative to positive. The Pongal harvest festival was taking place, and the color, activities, and excitement enchanted the students. One man was enthralled to the point of terror when he found the bullock cart he boarded was a part of a race. Another was delighted as the priests strolled down her street, chanting and blessing the animals. She felt as if she was in the midst of a culture, rather than observing from the confines of a scripted tour or through the glass walls of an exhibit. Another student felt a deep sense of inclusion as the family woke her early every morning with tea, and then brought her to the temple for morning prayers. One student felt warm and safe after the family performed a blessing over her on her first night in the home.

\section{Some Aspects of Tamil Domestic Religion}

My lectures on religion rang empty, and yet the local religion captivated the students. Later, when I was reading the first millennium Tamil classic, the Tirukkural or "Holy Speech," I understood the mismatch between my lectures and the experiences of the students. The Tirukkural describes two main lifestyles: that of the ascetic and that of the householder. The former is the domain of the type of philosophical systems and meditative practices that many Westerners are interested in and which my graduate education had prepared me to teach. The domain of the householder is very different. Whereas the ascetic renounces the world, the householder immerses himself in the world. Whereas the ascetic masters and uproots desire, the householder is to be a support for the world: "Five-fold his duty_ towards God, the manes, the guests, kindred and himself" (Tiruvalluvar \43).

As a support to the world, the householder is to foster a loving environment in the home. He is to make "love and virtue in a household reign" (\$45). "For parents, food touched by children’s hands tastes sweeter than nectar itself. The feel of children is rapture, and their prattle is finest music. They praise the pipe and the lute who haven't heard infants' lisping innocence" (\$64-66). Also, “The ground of domestic life is hosting guests on a generous scale" (\$81). A wealthy person who fails in hospitality is not wealthy but is "poor and stupid at once" (\$89).

In terms of being a support to the world, the giving of food has an especially important role. "The householder's line thrives when food is shared and wealth is honestly won" (\$44). "It's wrong to feed alone, with the guests left out" (\$82) "Who first feeds his guest, and eats what remains: seedless, he reaps harvests still. He that feeds his guests, yet awaits some more, will find welcome from the Gods” (\$85-86).

A further aspect of domestic religion in the Tirukkural is the subservient role of the wife. Whereas the husband is to be a support to the world, the wife is to be a support to the husband: "A good wife ... helps him in everything" (\$51). The wife's route to heaven is dedication to her husband, and she is to treat him with profound respect: "In full devotion to her wedded spouse, she wins the bliss of heaven" ( $(58)$. "On rising she bows to her spouse, her God" ( $(55)$. An essential 
aspect of devotion to her husband is chastity: "The world has nothing nobler than a wife with the Grace of chastity" (\$54). In fact, the ideal wife needs no protection or isolation to guard her chastity: "vain are all attempts to insulate her: the chaste wife, her own armour" (\$57).

The Tirukkural addresses many issues, but the final aspect to be discussed here is an "interreligious" dimension. In the first millennium, South India was a home to a large number of Hindus, Jains, and Buddhists. Further, due to trade with the Middle East, there were significant numbers of Jews, Christians, and Muslims in South India. Scholars have noted that the Tirukkural focuses mainly on virtue, and is vague on the specifics of religious belief and worship. For instance, one writer stated that "what mattered was not metaphysics, dogma, credal [sic] adhesion or standardised ritualism, but the reality of everyday life with its constant need for nuances of understanding and behaviour" (Iyengar 1988: 141). Possibly, the Tirukkural was a classic that members of multiple religions accepted, and thus was a bond in society. Even if it did not play that role in classic times, and even if the author/s did not intend it to play that role, it does today. In Tamil Nadu there are Hindus, Christians, and Muslims who look to it as expressing Tamil culture and values that are common to all of them, regardless of religion.

\section{Experiencing Aspects of Tamil Religion}

This section of the paper will show some of the experiences of the students and what they learned from them. To do this it will rely on the writings of eighteen students from the 2008 and 2009 runs of the course, which were the first and second times. ${ }^{2}$ These writings are from journal entries and examinations. The journal entries were a part of the students' homework assignments, and students were generally free to write on any aspect of their experiences. The examination questions involved a variety of issues, including the comparison of religions, gender, poverty, etc. (Without a spell checker and with the busy schedule of travel, the spelling and grammar in the entries ranges from distracting to atrocious. All the same, the entries convey important points.)

\section{Food and Hospitality}

The students exhibited little interest in the metaphysical aspects of Hinduism, but the issues of food and hospitality deeply impressed them. As one student wrote about his first morning during the homestays: "I woke up at 7 AM and was ushered outside to see the silk being stretched for [making] the saris. . . . After this, Senthil and I walked down these streets and met his 'relations.' We had tea in each house, and I narrowly missed having three breakfasts. It was amazing to me how willing the people were to share their good food with any guest who will come by. . . Everywhere we were offered food" (2008 J3). Another student wrote, the "Never have I felt so well taken care of. Food was always offered, if not forced upon me" (2008 J5). Also, "The food was great, although the quantity was always in excess and 'enough' was not in my mother's English vocabulary” (2009 $\mathrm{J} 2.1$.

\footnotetext{
2 The majority of the entries are from 2009. In 2008 I did not realize that student writings were valuable resources, so I saved very little from that year. Writings from 2011 and 2014 made essentially the same points as the entries from 2009. I changed all but one of the proper names in student entries to maintain anonymity. The name I did not change was the name of my institution, the University of St. Thomas. My citations for the entries indicate the year, whether the entry was an examination or journal entry, the particular student, and the page number. For instance, 2009 J2.1.
} 
Regarding the broader phenomenon of hospitality, there were an array of reports, of which the following is a small sample:

No where have I ever felt as welcomed as I have in India. The people here are by far the warmest and most friendly that I have ever met. Our host family had so little and yet they gave us everything, even their own bed and they did so happily. They always wanted us to be comfortable and happy and it meant so much to me to be welcomed like that. When we left they gave us a family photo of them in front of the Taj Mahal because they said they wanted us to be able to see it. I wouldn't give something as special to me as a family photo away to someone I had only known for a few days and would never see again and I think that says a lot about the Indian people. (2009 E3.1)

[We] went to visit a little boy. He was so happy to have us in his humble home. He had a small collection of toys and he gave us each one of his animals. I didn't want to accept the gift because I was taking all he had, but he gave with such love and excitement that I saw his true joy came in giving the gift itself. I could tell that it didn't even cross the boys mind that I probably live in a world where toys like that can be seen thrown away and neglected everywhere. He didn't take the time to think about how much I had and how little he had; he only smiled and gave it to me. (2009 E1.2)

Students did not simply experience the hospitality, but analyzed it, reflecting on its causes. The Tiruk.kural encourages hospitality because the householder should be a support to society. Further, it teaches that hospitality is essential to domestic life, and that good fortune comes to the hospitable. The students, however, identified a different issue. Many concluded that there is an intrinsic connection between the material poverty of the people and their hospitality. For instance, one student wrote that with few material possessions to occupy their attention, the villagers take delight in personal relations: "Life is about simple joys and making the people that surround you happy. It's not about matieral items that seem to be a main source of happiness and personal success in the United States" (2009 J1.2). Or, as the student in an above entry (2009 E1.2) wrote, the joy was in the giving.

One student assessed the situation as follows: "I'm okay with the trash on the ground, not having a mattress, eating rice everyday, shaking hands, and bathing from a bucket of cold water, because with that comes hospitality, love and compassion" (2008 J6). Another student saw the lack of material possession, the dedication to guests, and the dedication to religion as all a part of the same package: "This detachment lifestyle is so strong that it allows the people to focus on things beyond themselves. ... Only by detaching ourselves from material possessions and trivial desires are we able to attach ourselves to the people around us, the earth we live on, and God himself" (2009 E1.1).

Students went beyond experiencing the hospitality to analyzing it, and they went beyond analysis to learning values. As one student wrote, "Living so simply with an Indian family made me really think about what we truly need and don't need. I feel that after my experience with them I will be a much more giving person and reconsider what it means to host a guest. I will forever remember the generous spirit of the Indian people" (2009 E3.1). Also, "They give and give so much when they have nothing and when I think of how much I have at home and comparatively how little I give it 
seems shameful. In addition to being more generous and giving I would also like to be more welcoming and accepting like the Indian people” (2009 J7.2).

For the most part, the hospitality deeply enchanted the students. However, some had reservations about what they saw and experienced. For instance, although the standard policy in Tamil Nadu towards the outsider is hospitality, at least one student realized that some deep divisions lie within the society: "I stayed in my homestay at one of the wealthier homes and had a friend from the group and his family member come over to the house to play games. They left after only 10 mins. I later found out the family child wanted to leave because he felt uncomfortable in the situation. This reminded me of the reading from Tharror [Tharoor] with the story of the one child in the small town being an untouchable" (2009 J1.13). Also, whereas one student (2009 E1.1) saw the detachment of the people from material things as a cause of the devotion to guests and to religion, another student saw the devotion to religion as a cause of the material poverty: "After seeing all of these huge, intricate, time consuming temples everywhere you can't help but start to wonder what else could have been built or studied with that time. You have to start wondering how this country created a culture where god is given such prominence. Where so many place spiritual concerns above practical concerns" (2008 J2.1).

\section{Gender}

Today the world is undergoing rapid change, and the countryside of Tamil Nadu is no exception to this. My students observed that both the boys and the girls worked hard at school, that both genders often had ambitious career aspirations, and that the parents were supportive of the plans of both genders. In addition, in a large village where students stayed in 2011 and 2014, the president was a woman. Further, during the years that I ran the course, one of the key figures in Tamil Nadu's governance was a woman. This was Jayaram Jayalalithaa, who served numerous terms as Tamil Nadu's Chief Minister.

In spite of the changes taking place in Tamil Nadu, students observed things that fit stereotypical images of India and were consistent with the role of housewives as described in the Tirukkural:

It seems like they stay in the house a lot because only men can be seen on the streets. On all our bus rides I see men loitering on the streets outside the houses and shops while the women can only be seen peeking through the windows. They only are on the street if they are walking from one place to another, or have some other purpose in mind. Also, the two genders are very segregated. They usually talk and interact in same-sex groups. I've never seen a mix of men and women like there always is in the U.S. They even sit separately at mass. (2009 J13.2)

People were shocked that I actually wanted to play a game of Cricket, that I would talk and touch a boy, and my attitude that we are equal and I can do everything males do. I never thought about how it would feel to be in a country where there is this inequality. It's not fun, being told you can not play a game because you are a girl. (2009 E2.1)

The lower status of women here is very difficult to see and experience. My host mother told me she eats last because she has to wait to serve her husband and then eat from his plate herself and that kind of relationship is very strange to me. (2009 E3.1) 
Students reacted differently to the issue of gender relations than to the hospitality. Whereas the hospitality humbled the students and made them feel lacking, in terms of gender relations, students reported feeling grateful to be Americans. As one woman wrote, "Back in America, there are so many things I take for granted, like water, toilet paper, toilets, etc. A part of me knew I took these things for granted, but what I didn't realize what I took for granted was my freedom for equality as a female. . . It really brought me back to the ground and I learned that I am fortunate in America to have my equality rights" (2009 E2.1).

Some students tried not to rush to judgment, and attempted to stretch their perspectives, questioning whether the women of Tamil Nadu are necessarily unhappy. As one woman wrote, "It seems that the male is very dominant. . . . At this point in time, I can't tell if it's a suppresive system or if everyone is just happy and knows how to act and what their role is" (2009 J3.2). The student was suggesting that there is an emotional security in knowing one's role, and that the women find happiness in accepting their given roles. Congruent with what the student wrote, one could add that if one has no practical knowledge of other possibilities, one might be content with what one has. Another woman wrote,

And even outside of the mosque, and the short time we got to spend with the Muslims who worshiped there, there is seperations of the genders in Indian society. I'm surprised by how much it hasn't fazed me, or angered me. Perhaps its because it doesn't seem like anyone is unhappy about it. ... I really do believe that there is a mutual respect and understanding and Love between the men \& women who are together in India. I believe that any seperation of the sexes, is simply to keep people modest, and to respect women. Maybe that just my hopes making me see things this way, but I really do feel this way. (2009 J6.1-2)

One male student considered the gender roles in a larger context. Indians tend to value collective will, whereas Americans tend to value individual desire and initiative. A classic example of this is in the classic religious text, the Bhagavad Gita. In the Gita, the warrior, Arjuna, is on the verge of a battle. However, the opposing army consists of his cousins and their allies, so he is overcome with emotion and does not want to fight. However, his friend and charioteer, Krishna, has no sympathy. He explains to Arjuna that it is his duty, as a member of the kshatriya or warrior caste, to fight. Arjuna must set aside his individual wants and fears and focus on his duty.

The Gita gives religious significance to carrying out one's duty. As Krishna, who is an incarnation of God, says of himself, "What if I did not engage relentlessly in action? . . These worlds would collapse if I did not perform action; I would create disorder in society, living beings would be destroyed' (Miller 1986, 3.23-24). Furthermore, Krishna instructs Arjuna that he should carry out his duty in a selfless manner, not thinking about the potential gains and losses, but simply act out of a sense of duty.

A male student, in light of the Gita, reflected on the role played by his host mother. He came to regard the submission of her individuality to her given roles and duties as an admirable thing:

The mother of my family was very nice, very devoted to her family and religion, and very motherly. She was 35, her husband 50, and initialy broke my heart when she told me she 
never leaves home, and had never been any where except Polur and Tiruvannamalai. Though as my 1 week stay went by, this sadness that I initially felt would turn into admiration.

Going into this trip I had the idea that a woman as a stay-at-home mom our a housekeeper was a degrading, unimportant, or surrendering role. The mother of the house taught me otherwise. She was very proud of how she carried out her "duty".-_Almost like Arujuna carried out his duty even when he realized he had no other choice he did what he had to with pride and did his action out of duty and not for the outcome-And the week with her allowed me to see how important her "duty" is to the family. She worked very hard and she was a great mother and she embraced her role, she did not regret it or ask for anything in return $(\mathrm{J} 8.4)$

\section{Religious Diversity}

As discussed above, South India has an ancient history of religious diversity. Members of different religions often live side-by-side, yielding an interreligious tapestry that is hard for a Westerner to imagine. Tharoor describes this tapestry in his state of Kerala: "Kerala is a microcosm of every religion known to the country; its population is divided into almost equal fourths of Christians, Muslims, caste Hindus, and Scheduled Castes (the former Untouchables)" (Tharoor 1997: 68). "Keralites tend to take pride in their collective identity as Malayalis [Indians of Kerala]; our religion, our caste, our region, come later, if at all" (Tharoor 1997: 70-71). "A Malayali Hindu feels instinctively closer to a Malayali Muslim than he does to a Punjabi Hindu" (Tharoor 1997: 77). Likewise, as discussed above, there is a common Tamil culture, expressed in the Tirukkural, that many Tamilian Hindus, Muslims, and Christians share.

Because members of different religions often live side-by-side, and often have a common, local identity to bind them together, there can be an interreligious dimension to the home and village. For instance, many Catholic homes follow certain Hindu customs of worship, such as waving oil lamps before religious icons and processing with incense throughout the house. In addition, members of more than one religion often participate at religious festivals and celebrations. In fact, an interreligious component is inscribed in some festivals. A good example is the celebration of the god Ayappa at Erumely, which involves processing through a mosque.

In the West, religious boundaries are generally conceived, by both adherents and non-adherents, as rigid and absolute. Hence, exposure to the interreligious aspect of the countryside makes a profound impression on the students. Three examples that stood out in journal entries drawn from 2008 and 2009 were a gathering of Muslim leaders in a Catholic home, a Pongal celebration at a Catholic school, and the celebration of Ayappa at Erumely.

Regarding the first example, the Indian coordinators of the course invited local, Muslim leaders to a Catholic home to speak to the students. The three leaders wore their dhotis in the local fashion of Muslims, and one of them had the classic mark on the forehead that results from a lifetime of daily prostration. The three men sat beneath a statue of Mary and a painting of Jesus with his sacred heart exposed. Muslim and Catholic imagery were thus juxtaposed, and both the Muslim leaders and the Catholic family looked at home and comfortable with each other. One student reported,

When the Muslim leaders first entered George's home I was shocked. Back home I would never imagine that people of one faith would openly invite those of another faith, particularly Islam right 
now, to almost preach about their religion. It would almost seem like a heretic move in America. The way George and his family invited the speakers into their homes as not just guests but wise scholars impressed me more than any thing I'd seen in America. It was just one of the first glances I had of the accepting and tolerant nature of the Indian people ... (2009 J5.1)

That same year, 2009, my students attended a Pongal celebration, held at the Catholic grade school that was coordinating the homestays. This harvest festival involves songs, games, dances, and other performances. It also involves preparing the pongal dish, a special sweet rice that boils out of the pot, indicating abundance, like America's horn of plenty. After the pongal overflows, it is placed on a banana leaf plate along with other food items. The celebrant then holds the plate high in the air, as an offering to the sun god.

At the Pongal celebration at the school, all the students, which included Hindus, Christians, and Muslims, participated: "It was awsome to know that many of the students we had met were Hindu, \& some Christian, and some Muslim, but they all could get together to celebrate the same holiday" (2009 J6.3-4). Further, the school principal, who is a Catholic priest, was the master of ceremonies. As the master of ceremonies, he raised the food high in his hands, above the assembly, towards the sun: "Father Thomas blew my mind when I saw him preparing a meal for the sun God at his catholic school" (2009 J8.5-6).

The above two examples were in village contexts. The third example that stood out in journal entries was the pilgrimage site of Erumely. It is one stop on the way to Sabarimala, where Hindus celebrate the triumph of the god, Ayappa over the buffalo demon, Mahisha. In Erumely, pilgrims joyfully dance from the temple to the mosque, and dance through the mosque. A legend behind this custom is that the imam at the mosque, Vavar, assisted Ayappa in his quest to conquer the demon. One student wrote,

As we entered the village, there was a mass of convergence of these pilgrims in a culmination of color, the joyous clashing crescendo of song, dance and instruments. Brown bodies glowing in the brilliant painted dyes moved as massive waves down the vender crammed streets. I have to admit, to the unaccustomed visitor as myself - I felt a fleeting wave of intimadation as we left the bus to walk through the throng of celebrants. But soon we found ourselves caught up in revelry.

But the amazing site of the entire festival for me was watching the Hindu's pilgrims pass between their temple and into the Muslim mosque as a way of respecting and embracing each other's religion. ${ }^{3}$ Wow! That is impactful and truly an example for the world. (2008 J1.1)

In 2009, the second run of the course, the interreligious ramifications of the site were brought home even more strongly. The students joined the pilgrims by dancing down the street with them. At least one student reported surprise at seeing the Hindu pilgrims being so accepting of people of a different race, culture, and religion: "They were so excited about everything and invited us to join

\footnotetext{
${ }^{3}$ Corrine Dempsey suggests that traditions such as these are not so much a matter of embracing the other religion itself, but of embracing the community that belongs to that other religion. She regards such occurences as expressions of community relations (Dempsey 2001).
} 
them. We danced in the street with them. They threw colored powders all over us and gave us branches to wave to the beat of the music. I was surprised that they were so accepting and encouraging of us" (2009 J3.3-4).

Given the rigidity of religious boundaries in the West, these experiences were surprising to the students. Some developed explanations in their journals. For instance, one student saw it as a natural extension of the hospitality of Indians: "After my stay with the host family my idea of hospitality has totally changed. It's all part of the friendly and positive outlook that they all have. They are so accepting of everyone regardless of religion" (2009 J7.2). Another explained the ready acceptance that the group experienced at Erumely in terms of joy. The festival is a celebration of Ayappa's triumph, and that joy lends itself to sharing: "I guess when religion is a source of joy it can easily be shared with all. For them, it didn't matter that we were from a different country, culture, and religion, they just wanted to share the goodness of their tradition with us" (2009 J3.4).

The above two students concluded that hospitality and joy can draw people together across religious boundaries. Somewhat similar to this, another student reflected on commonalities that easily communicate themselves across boundaries. She, as a complete outsider to the culture, could grasp aspects of the Pongal festival. If she, as an outsider, could grasp it, it is not surprising that Hindu, Christian, and Muslim Indians all felt comfortable participating: "The activities were fun to watch and easy enough to understand. I understood the whol symbol behind the pot flowing over, even before anyone explained it. Maybe that the appeal of the holiday, because it goes beyond religion and cultures, and celebrates something we all can understand. Being grateful, and hoping for the next harvest to be so abundant, that our pots 'flow-over.' It was awsome to know that many of the students we had met were Hindu, \& some Christian, and some Muslim, but they all could get together to celebrate the same holiday" (2009 J6.3-4).

The above student reflected on the Pongal celebration in terms of commonalities to which all can relate, but another student saw in it a remarkable juxtaposition of differences: "Father Thomas blew my mind when I saw him preparing a meal for the sun God at his catholic school during a prepongol day celebration" (2009 J8.5). His explanation was that Indians have a skill at embracing differences: "Traveling from city to city, visiting temple after temple I noticed how each spot had its own rituals and each Indian had their own answees. ... Despite the lack of unimformity and the differing beliefs everyone gets along. In fact, I think that they embrace it. Embracing these differences is not just a Hindu way of thought, it is an Indian way of thought and that is why . . . Father Thomas celebrated-led the celebration—the Hindu holiday Pongol" (2009 J8.6).

Students felt that they, and the world in general, had a lot to learn from these examples. The student who was transfixed by seeing the Catholic priest holding the offering up to the sun wrote:

I mean, recently it seems like evvery thing on the news is about how our differences, be they political, religious, or otherwise, are a cause for seperation, a cause for hate. Even at thome at St. Thomas [the students' institution in the United States] I feel like my differeing opinions are what is ponted out rather than the similarities.

Because of the many frustrating experience I've had at UST [St. Thomas] it was completely uplifting to see St. Anne's school and how the teachers and students co-existed. ... 
... Seeing . . F Father Thomas share his life with his students and his students life with his own gives me so much hope ... (2009 J8.5-6)

A little less dramatic, another student stated, 'It excites me to think that one can practice one's own religion while still having knowledge about other religions. I love the idea of true acceptance even if you disagree with other's religious beliefs. I can already tell that India has a lot to teach me" (2009 J4.2-3).

\section{Developing a Suitable Pedagogy}

My original lectures focused heavily on abstract, theological themes. However, although India is the home to some of the world's most abstract philosophies, a trip through India is not necessarily a conducive context for the foreigner to study such systems. The reason is that the environment draws the mind outward, rather than reflectively inward. To begin, the sights, sounds, and smells yield the "sensory overload" that foreigners often report. Further, the cultural context is so alien to many Westerners, that the mind is occupied with many practical concerns, such as poverty and environmental pollution.

When I first began designing the course, I essentially conceived of the site tours as a PowerPoint presentation, as photos demonstrating themes covered in lecture. I later developed suitable lectures by reversing this relationship, by developing lectures to illustrate the sites, unlocking their meaning. Further, I contextualized the lectures at the start of the term by telling the students that the lectures would help them to understand the sites and their experiences better, and that that would help them enjoy the sites and experiences more. In addition, I used lecture to give brief orientations sessions, explaining what they should expect, and what would be expected of them. Students thirst for some guidance to this foreign world, and such lectures gave them that guidance.

A disadvantage of this approach is that it yielded a disorganized effect, since lecture was organized in terms of sites, rather than a logical progression of themes. Also, as the weeks went by their patience with lecture ebbed. That was, in part, because of cumulative physical and emotional exhaustion, and because they were feeling more at home in India, and thus wanting less guidance. Lecture worked best in the first week or so, and group discussions became more appropriate as the trip progressed.

Group discussions became essential to my pedagogy. My lectures in later years were more appropriate for the students' experiences than my lectures in earlier years, but even those later lectures only touched the surface of what was on their minds. Deep inside, a profound encounter between two very different cultures was taking place. Discussion, far more than lecture, was able to plumb those depths.

Although discussion could explore and unpack what was happening inside the minds of students, they generally would not share without some sort of prompt or guidance. An excellent prod was having them read short passages that reflected their experiences. I had a broad array of readings for this purpose, most of them being journalistic accounts. I had the students read them before class, and portions of them aloud in class. I asked them if the reading reminded them of their experiences, and this initiated discussion. Through these discussions, students gained perspective and expressed what was on their minds. 
Discussion was an opportunity for the students to learn not only about India, but also about America. America is the natural reference point for the students, and is thus a topic implicit in the discussions. On the first trip, it became clear to me that students tended to essentialize their twenty years of experience in America, not realizing that their experiences were situated in particular time and place, and were not universal. For instance, they experienced Indian culture as very alien, but in some cases, the differences were not so much between India and America, but between rural and urban. I addressed this is by having the students read an account by my mother of her hometown on the prairie in the 1920s and 1930s. I then asked the students to identify similarities between her account and their experiences in Tamil villages.

I addressed the students' essentialism in other ways, too. For instance, I had them read accounts of gender relations and women's behaviors in America prior to the 1960s. I also had them read accounts of the pollution that came in the wake of the Industrial Revolution and before today's environmental awareness and legislation. That way the students realized that their experiences of clean cities and gender equality are not intrinsic to the West, but are recently scored victories.

In addition to the points made above, there are many other issues that could be explored in the future. For instance, although the West claims the Bible as its own, the Bible is much closer in place and time to the world of the Tirukkural than to contemporary European and American cultures. What similarities could students find between the two texts, especially in terms of hospitality, gender relations, and the cultivation of virtue? Other similarities between the Bible and South Indian religion include rules about purity and pollution, and the layout of temples. Such comparisons would be another way to help students grow out of essentialistic views of both the West and the Bible.

Another issue to be explored more deeply is personal choice versus collective will. For instance, students often found that, while staying in the homes, their host families treated their personal preferences as irrelevant. One student wrote, "Getting to know Rajesh better, I discovered that he was very worried about my well being and behavior during my stay. He was always there to tell me exactly how to act, how to cross the street, what I did or did not want in the shops, when and how I should pray. Of course, it was all well intentioned, but the constant comands from a 14 year old boy began to ware on me by the end of the week" (2009 J2.1). I would like students to explore more deeply their reactions to this guidance from their homestay hosts. I would like them to reflect on it as members of a society that strongly values personal choice, and in light of Krishna's message to Arjuna in the Bhagavad Gita.

Lastly, it would be good to consider some of the major course themes in light of each other. For instance, both the Bible and the Tirukkural espouse hospitality and subservient roles for women. Is there something about hospitality and traditional gender roles that go together? Further, the Gita espouses surrender of the individual will to the collective will, and students could reflect on this in relationship to India's religious pluralism. Although each individual must conform to the duties of his or her group, it is also understood in the Gita, and in other classic Hindu sources, that a variety of groups exist, each with its particular duties and ways.

\section{References}

Dempsey, Corinne G. 2001. Kerala Christian Sainthood: Collisions of Culture and Worldview in South India. Oxford: Oxford University Press. 
Iyengar, K. R. Srinivasa. 1988. Postcript to Tirukkural: Lights of the Righteous Life, by Tiruvalluvar, trans. K. R. Srinivasa Iyengar. Calcutta: M. P. Birla Foundation.

Miller, Barbara Stoler, trans. 1986. The Bhagavad-Gita: Krishna's Counsel in Time of War. New York: Bantam Books.

Tharoor, Shashi. 1998. India: From Midnight to the Millennium and Beyond. New York: Harper Perennial.

Tiruvalluvar. 1988. Tirukkural: Lights of the Righteous Life. Trans. K. R. Srinivasa Iyengar. Calcutta: M. P. Birla Foundation. 